\title{
Corpos dissidentes afro-diaspóricos e suas poéticas contemporâneas no espaço urbano
}

\author{
Paola Barreto Leblanc \\ Doutora em Poéticas Interdisciplinares (PPGAV - UFRJ), atualmente é professora de Artes, Estéticas e Materialidades no Instituto de \\ Humanidades Artes e Ciências da UFBA. \\ Contato: paoleb@gmail.com
}

\section{Lucas Brasil Vaz Amorim}

Graduando do Bacharelado Interdisciplinar em Artes do Instituto de Humanidades, Artes e Ciências da UFBA e pesquisador do Programa Sankofa (PROAE - UFBA).

Contato: lukas.brazyl@gmail.com

\section{RESUMO}

Nesse trabalho desenvolvemos uma breve análise sobre a relação entre corpos dissidentes afro-diaspóricos, território urbano e arte contemporânea. Para investigar estas categorias, partimos de um referencial interdisciplinar, analisando, a partir de uma perspectiva decolonial, subjetividades contra-hegemônicas atravessadas pela experiência corpográfica - racializadas, generificadas, (des)classificadas -, bem como práticas artísticas específicas que tensionam tais experiências.

Palavras-chave: decolonialidade; corpos afro-diaspóricos; arte contemporânea; espaço urbano.

\section{ABSTRACT}

In this paper we develop a brief analysis of the relationship between afro-diasporic dissident bodies, urban territory and contemporary art. To investigate these categories, we start from an interdisciplinary framework, analyzing, from a decolonial perspective, counter-hegemonic subjectivities traversed by the body experience racialized, gendered, unclassified - as well as specific artistic practices that tension such experiences.

Key-Words: decoloniality; afro-diasporic bodies; contemporary art; urban space. 


\section{Introduçáo}

Nesse texto buscamos pensar o corpo não como categoria universal, mas, pela via contrária, o concebemos no plural. Para além de um jogo semântico, é na pluralidade dos corpos que compreendemos aquilo que Paola Berenstein Jacques (2011) conceitua como experiência corpográfica no ambiente urbano. Inscrevendo ações de sujeitos errantes, que riscam as vias urbanas de metrópoles governadas por necropolíticas higienistas, os corpos na rua encenam embates entre um modelo que se apresenta como universal - homem, cis, heteronormativo, branco - e os "outros" ou "minorias" que produz. Neste sentido, quem foge à norma não só traça uma corpografia outra, como vive um estado de corpo e experiência de alteridade sob uma lógica perversa (SODRÉ, 2018).

A partir dessas consideraçôes iniciais, é importante destacar as noçóes de raça, gênero e classe para pensarmos possíveis encruzilhamentos entre corpos plurais, o ambiente urbano e as intervençôes propostas por artistas contemporânexs brasileirxs, que experimentam, em suas poéticas, tanto seus próprios corpos, como a ambiência que os incorporam. Desse modo analisamos, a partir de uma perspectiva decolonial, subjetividades contra-hegemônicas atravessadas pela experiência corpográfica — racializadas, generificadas, (des)classificadas —, bem como práticas artísticas específicas que tensionam tais experiências.

Partindo de um breve contexto histórico, se faz necessário discorrer sobre os processos de territorialização, desterritorialização, reterritorialização e racialização dos corpos, incluindo aí os processos de constituição do território simbólico e suas rasuras riscadas, compreendendo esse conjunto de questôes por meio do balaio tático da pedagogia das encruzilhadas (RUFINO, 2016). Da mesma forma refletimos sobre modos de rexistência dos corpos os quais chamamos de dissidentes afro-diaspóricos, pensando em produçóes de sentido e subjetividades a partir da poética de artistas negrxs como Musa Michelle Mattiuzzi, Castiel Vitorino Brasileiro e Paulo Nazareth.

\section{Corpos negros em diáspora: outras encruzilhadas}

Sabemos que os processos sociohistóricos de territorialização das metrópoles brasileiras constituíram espaços distintos de privilégios e de segregação (SODRÉ, 1988; NASCIMENTO, 2006). Os ideais de progresso e civilização foram pautados, desde a época colonial, em um projeto político de nação que segrega pretos, mulheres e identidades que não se enquadram na heteronormatividade cisgênera. Através das desigualdades sociais percebidas na contemporaneidade, é possível fazer um movimento sankofa ${ }^{1}$, olhando para o passado e compreendendo as agruras do presente.

Dessa forma, pensamos os territórios da cidade como campos de disputa de corpos autorizados e náo-autorizados à plena fruição da vida. Contudo, não nos interessa apenas a denúncia e sim a compreensão de processos complexos que envolvem tanto os corpos como os territórios, sob uma perspectiva que desobedeça a colonização do pensamento. Assim, localizando-se em outros entendimentos de espaço e tempo, nos aproximamos das táticas de re-significação dos povos africanos após serem submetidos ao exílio no Brasil, para nos guiar nesse primeiro momento.

Como afirma Érika do Nascimento Pinheiro sobre o conceito de territorialidade, "é a forma como o ser humano se relaciona com o espaço, com o real, 
na busca de identidade" (2009, p. 4). Os povos afro-diaspóricos desenvolveram estratégias para reconstruir laços identitários em um novo território, ou seja, com a desterritorializaçáo iniciou-se um processo de reterritorialização a partir de relaçóes étnicas, reconfigurando sistemas sóciopolíticos através da formação de redes sóciorreligiosas ${ }^{2}$, assim formando o que hoje conhecemos como candomblé.

Com base nesse movimento, nos questionamos o que está implicado nas relações entre corpos negro-africanos e seus descendentes afetados pela diáspora, e quais as transformaçóes no território material e simbólico decorrentes das rasuras provocadas por modos distintos de viver o lugar que se habita. Para isso, é necessário entender que a experiência do corpo negro se diferencia por uma construçáo a qual foi submetido pela biopolítica colonialista branco-européia: a racialização.

Como afirma Muniz Sodré: "No centro disso tudo, opera uma hermenêutica do corpo - sem o corpo, o racismo é inconcebível." (SODRÉ, 2019, p.10) A "raça" se traduz como construção da modernidade para classificar hierarquias entre os seres humanos, com fins de estabelecer relaçôes de poder. Qualificando imageticamente - pela visão projetada ao corpo materializado, cognitiva e culturalmente - pela deslegitimação dos saberes, a inferioridade de um grupo.

Assim, há uma desumanização do sujeito negro ao se instituir o corpo branco como padrão, “[...] na incontestável igualdade material do corpo humano, o racismo infiltra-se sob forma de um valor eurocêntrico e pleno, supostamente universal, que cria a falsa universalidade do inumano pleno, o diverso." (ibidem, 2019 p. 11)
Portanto, é assente nesta compreensão do "Outro" que o corpo negro é percebido em sua performatividade cotidiana no espaço urbano, desde o período escravocrata até os dias atuais, tornando impossível conceber analiticamente o corpo como categoria universal. Logo, ao deambular pelas vias da cidade, as marcas que se salientam na experiência de quem vive os efeitos do alterocídio são múltiplas - a violência do racismo estrutural se personaliza no jogo da alteridade.

Seguindo esse pensamento a respeito de tais marcas, a pesquisadora e artista interdisciplinar Grada Kilomba discorre sobre o trauma colonial do sujeito negro, denominado pela autora como ferida:

Dentro dessa infeliz dinâmica, o sujeito Negro torna-se náo apenas o 'Outro' o diferente em relação ao qual o 'self' da pessoa branca é medido - mas também 'alteridade' - a personificação de aspectos repressores do 'self' do sujeito branco. Em outras palavras, nós nos tornamos a representação mental daquilo com o que o sujeito branco não quer se parecer. Toni Morrison (1992) usa a expressão "dessemelhança", para descrever a "branquitude" como uma identidade dependente, que existe através da exploração do 'Outro', uma identidade relacional construída por brancos(as), definindo eles(as) mesmos(as) como racialmente diferentes dos 'Outros'. Isto é, a Negritude serve como forma primária de alteridade, pela qual a branquitude é construída. O 'Outro' não é outro per 
se; ele/ela torna-se tal através de um processo de absoluta negação. (KILOMBA, 2010, p. 175)

Neste sentido, pensando mente-corpo como unidade, a psique do sujeito racializado é marcada por esse olhar do outro branco, fundamentando experiências sobredeterminadas de ser e estar no mundo através de olhares bélicos lançados ao corpo negro. Por exemplo, um homem negro ao transitar em determinados espaços de sua cidade, atinge o imaginário coletivo como significante de violência e criminalidade - projeção que opera como forma de justificar a desumanização desse corpo. Não obstante, ele pode ser atingido por oitenta tiros ${ }^{3} \mathrm{em}$ uma ação militar efetivada por representantes de instituiçóes ligadas ao poder do Estado. Dito isto, corpos racializados são marcados duplamente na dimensão do real e do simbólico, de forma que lhes é desautorizada a própria vida.

Apesar das marcas indeléveis do colonialismo, corpos afro-diaspóricos rexistiram e rexistem através de táticas de reterritorialização e organização coletiva guiadas por saberes ancestrais, bem como práticas artísticas contemporâneas que têm produzido narrativas potentes a partir desses corpos.

Isto posto, além da experiência corpográfica analisamos o território configurado como campo de disputa, onde rasuras são riscadas em formas de encruzilhada, e transgressões exunicas (de Exu) são elaboradas por corpos "Outros". É a partir de brechas, becos, vielas, espaços vazios deixados pelos grupos dominantes que se incorpora a potência transformadora do território.

\section{A potência das encruzilhadas: reconstruindo territórios}

Para nos guiar em meio a diferentes caminhos que se apresentam, foi preciso trazer para nossas elucubraçóes a pedagogia das encruzilhadas, que se estabelece "[...] como um projeto político/epistemológico/educativo anti-racista/descolonial." (RUFINO, 2016, p. 2). Esta forma de conceber o saber descarrega os feitos do projeto monorracionalista moderno, em contraposiçáo às várias possibilidades que as encruzilhadas da descolonização do pensamento nos proporcionam. E assim, compreendemos que a instrução teórico-metodológica se dá não somente a partir de modelos eurocêntricos, mas também e sobretudo na investigação de formas e criatividades resistentes, com as quais corpos dissidentes afro-diaspóricos sobreviveram e sobrevivem no ambiente citadino.

O deslocamento destes corpos, bem como as territorialidades rasuradas por eles, podem ser compreendidos através da sabedoria de Exu. A noção de cruzo proposta por Rufino (2016, p. 6), nos diz sobre a diversidade de saberes e suas interaçóes, revelando as encruzilhadas epistemológicas como campo constantemente movimentado por conhecimentos cosmopolitas, perpassados pela flexibilidade das transformaçóes. Desse modo os saberes da pedagogia das encruzilhadas se estabelecem como operações interessantes para compreender a reterritorialização de grupos subalternizados na cidade, invocando, nas práticas do caos, questionamentos de verdades pré-estabelecidas em territórios formatados para excluir e violentar determinados corpos. Esse modo de proceder chamamos exunico. 
É importante destacar o lugar do corpo novamente, contudo neste posicionamento político-epistêmico. Assente na pedagogia das encruzilhadas, o corpo traduz-se como "campo inventivo", território material, simbólico e político, onde se possibilitam práticas de (re)invenção de mundo, produção de vida, novos espaços e organizaçóes comunitárias, a partir da cosmovisão negro-africana na diáspora. Nesta perspectiva, o trauma do deslocamento circunscrito nos corpos afro-diaspóricos não os restringe de revitalizar suas potências originárias, muito menos de reconstruir territórios. À vista disso, o autor reforça nosso pensamento:

Assim, à medida que o corpo negro foi desterritorializado, através de seu suporte físico e de suas potências, foi tornando-se capaz de recuperar e ressignificar memórias comunitárias, reconstruindo formas de sociabilidade e práticas de saber. O corpo é a instituição máxima e integrante da experiência em comunidade, é ele o elemento que institui e organiza o projeto comunitário. (ibidem, 2016, p. 11).

Balançados pelo barravento dos ensinamentos de Exu, nos questionamos sobre como pensar territorialidades e ambiências que são produtos e produtores de movimentos e estéticas impulsionados por corpos dissidentes. Quais são estes territórios e o que os move? A historiadora Beatriz do Nascimento nos traz uma possível resposta através de seu conceito de quilombo, que articulou grande parte de sua jornada como pesquisadora. ${ }^{4}$ Além de se constituir como um sistema alternativo de ocupação territorial por povos negro-africanos, Quilombo para Nascimento é uma categoria científica, "confundido, num bom

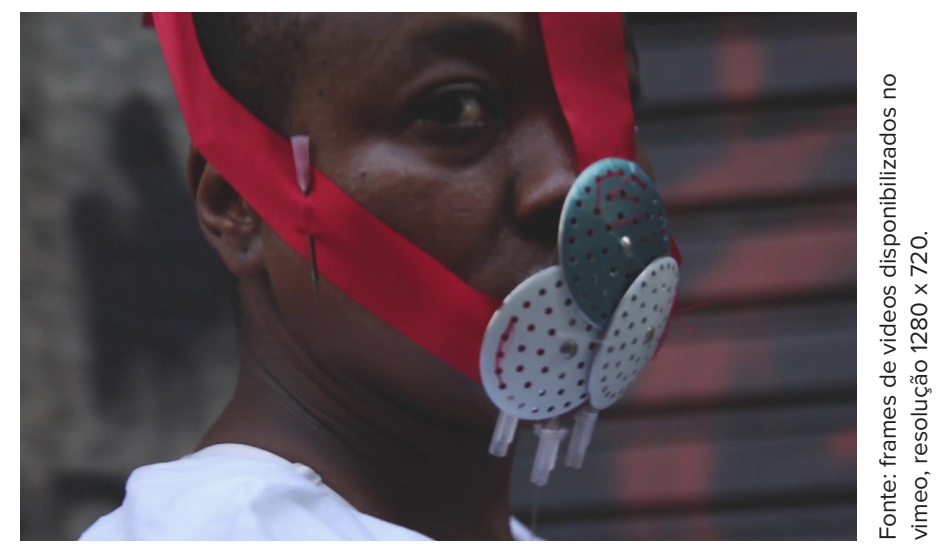

"Experimentando o vermelho em dilúvio II" Musa Michelle Mattiuzzi (2016).

sentido, o território palmarino com a esperança de um Brasil mais justo onde haja liberdade, união e igualdade." (1978; 2006, p. 123)

Em seu texto Kilombo e memória comunitária: um estudo de caso (1982; 2006), Nascimento vai além da visão de sobrevivência e resistência cultural que associamos a esse processo de reterritorialização. Ao cunhar o termo continuidade histórica para conceituar o fluxo de vida do grupo negro sem quebras ou clivagens, a autora analisa a constituição de sistemas comunitários alternativos contemporâneos, como favelas e bairros periféricos nas metrópoles brasileiras, onde a populaçáo se reorganiza, apesar e devido ao racismo estrutural da sociedade.

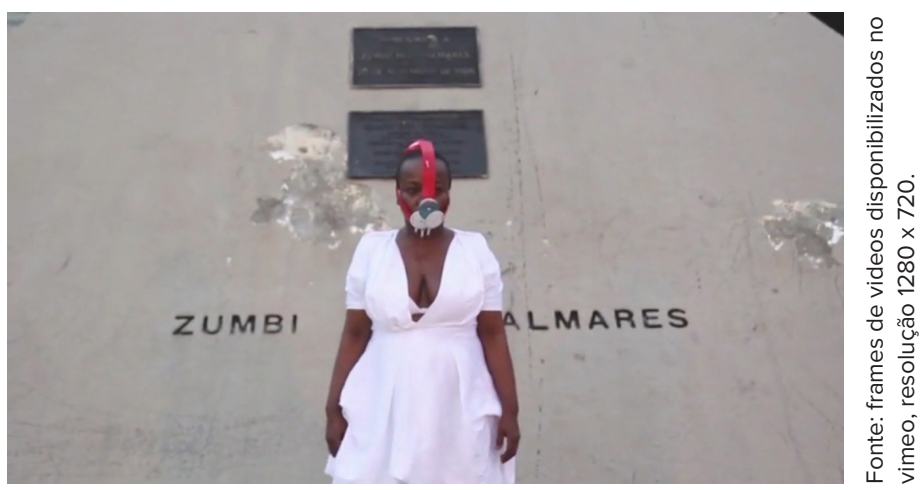

"Experimentando o vermelho em dilúvio II" Musa Michelle Mattiuzzi (2016). 
Logo, voltando a noção de corpo como território proposta pela pedagogia das encruzilhadas, a retomada corporal e de suas potencialidades é imprescindível como caminho de reterritorializar memórias e saberes. Além da construção e retomada de territórios, o que subjetividades afro-diaspóricas dissidentes produzem a partir de seus próprios territórios existenciais, ou seja, por/para seus próprios corpos? Quais plataformas ou modos de produção do sensível permitem o diálogo entre essas existências e o espaço urbano?

\section{A encruzilhada da arte negra: espada que abre caminhos}

Alguns feitos produzidos no âmbito da arte contemporânea nos mostram possibilidades exunicas de criar narrativas que versam sobre vida, morte, dor e cura do corpo preto dissidente. Elencamos aqui três artistas negrxs brasileirxs que têm se destacado no cenário da arte contemporânea nacional, e cujas poéticas ressaltam o poder das encruzilhadas através de suas práticas artísticas. Além disso, suas obras dialogam com as fissuras da urbanidade, na medida em que as ações foram feitas em espaços públicos, todas elas guiadas pelo campo da performance.

A ideia de "quebra" é o que pode se aproximar de uma tentativa de definição da performance para Eleonora Fabião (2009), visto que há uma quebra literal de normas e hábitos através da ação performativa, tanto para quem propóe quanto para quem a assiste. Contudo, essa "quebra" não vem do simples ato de propor uma ação provocativa, ela é elaborada como um programa (Deleuze; Guattari, 1999, p. 12 apud Fabião, 2009, p. 237), que não tem ensaio prévio, mas que abarca
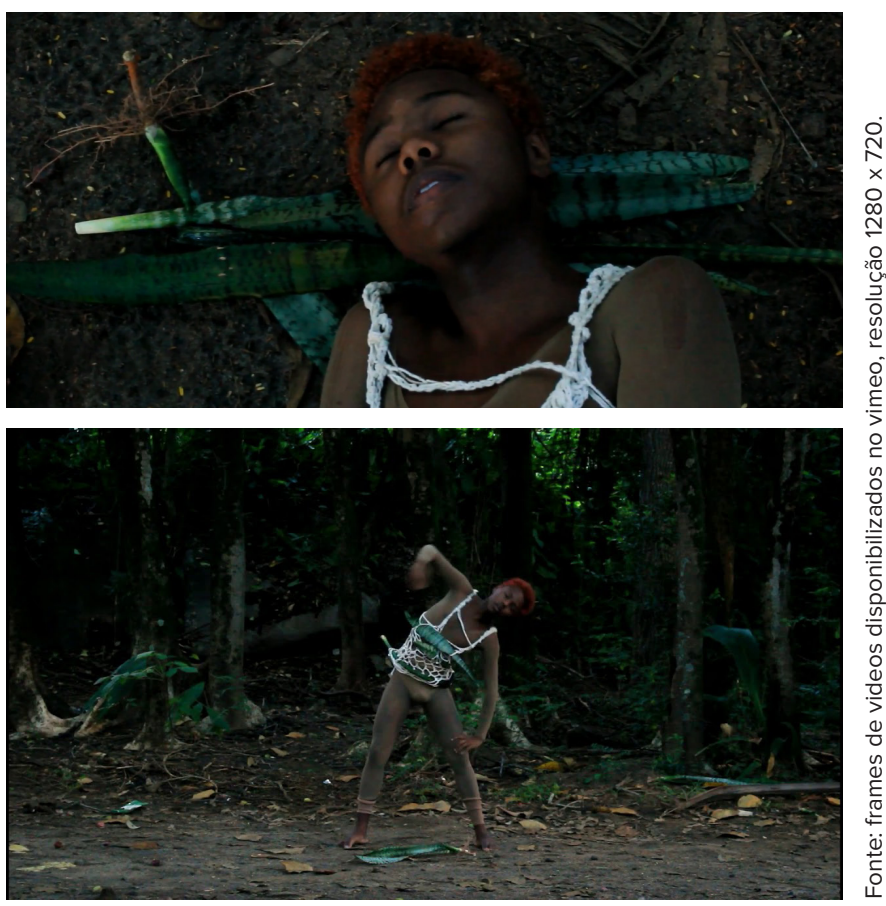

"Como se preparar para a guerra" frame do vídeo-performance. Castiel Vitorino Brasileiro (2018)

uma complexidade de conteúdos pensados pelo autor da obra, colocando o seu corpo como o veículo da ação. Com isso, os "programas criam corpos", ou seja, uma multidimensionalidade de significados entre quem performa e quem é afetado pela performance, constante emanação de experiência. Pode-se insinuar que a experiência é um terceiro corpo.

Para falar de performance e corpos negros, a artivista Musa Michelle Mattiuzzi (2013) escurece o conceito de programa e aponta a intensidade de suas ações artísticas desempenhadas por meio do seu corpo negro "máquina de guerra":

Performar um programa de açóes é uma possibilidade de lançar questóes, ou melhor, me lanço no espaço, aproveito todas as fissuras, coloco meu corpo em 


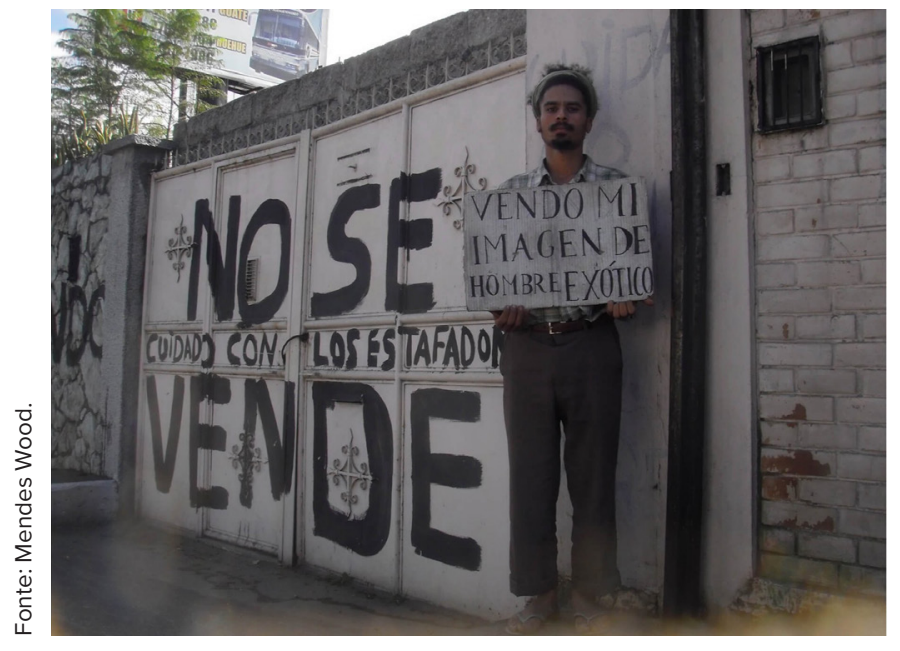

Paulo Nazareth, sem título, da série Notícias de América, 2011, impressão fotográfica sobre papel algodão, $60 \times 80 \mathrm{~cm}$.

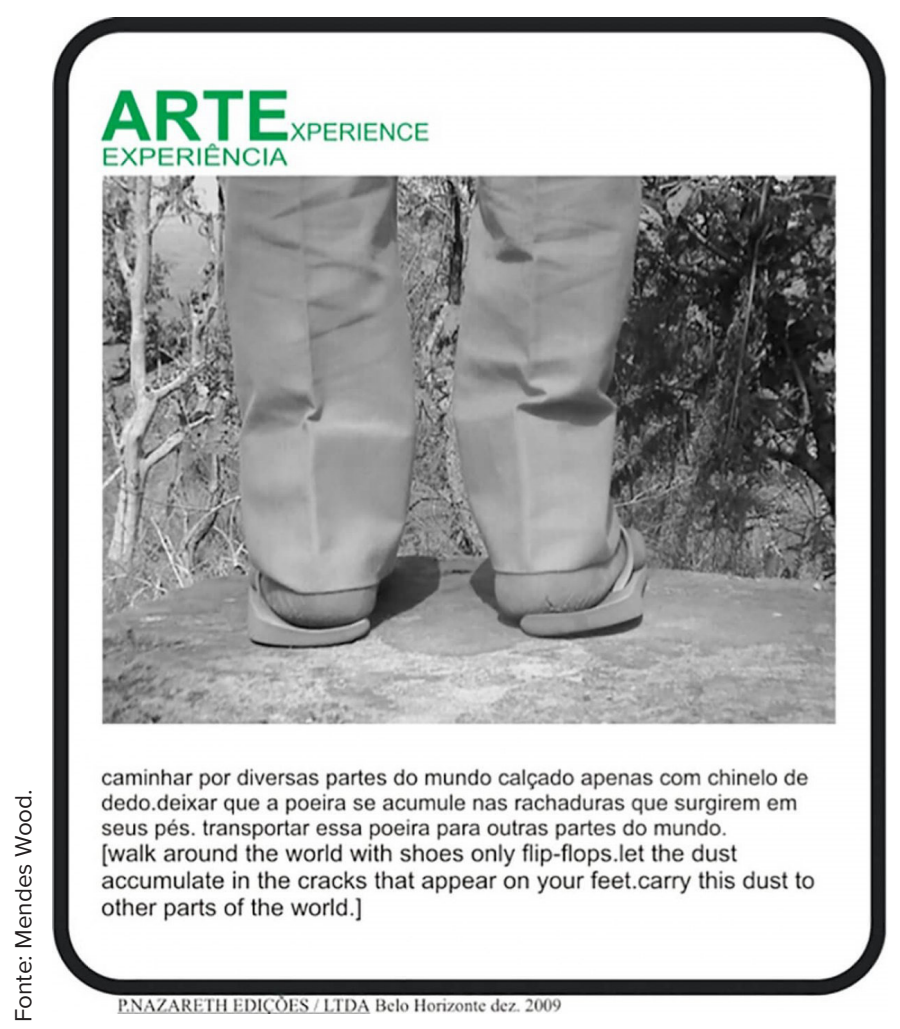

Paulo Nazareth, Aqui é Arte - Planfleto, 2009, impressão fotográfica sobre papel algodão risco diante de todos os preconceitos e questiono todos os adjetivos lançados sobre ele. Provoco o diálogo em tempo real. (MATTIUZZI, 2013, p. 3)

$\mathrm{Na}$ intervenção Experimentado o Vermelho em Dilúvio II (2016), Mattiuzzi caminha pelas ruas do Rio de Janeiro, vestida de branco e utilizando uma máscara presa ao seu rosto por agulhas, que, ao ponto que lhe provoca dor e silêncio, evidencia o trauma da colonização que fere seu corpo. A performance dialoga com o referido texto de Kilomba (2008), no qual a autora trata do silenciamento real e simbólico do sujeito negro; outrora pela imposição dos senhores no uso da máscara de ferro que impossibilitava o escravizado de falar e comer, nos dias de hoje pelo racismo estrutural que atualiza formas de silenciar.

Nesta jornada à estátua de Zumbi de Palmares, no centro do Rio, a performer caminha experimentando os olhares de estranhamento, "agulhadas" coletivas, sendo tomada pelo dilúvio vermelho de suas feridas coloniais. Ao chegar ao seu destino, retira a máscara de sua face, deixando escorrer sangue e lágrimas. A proposta de Mattiuzzi exprime uma série de atravessamentos da experiência do corpo negro no mundo, e é a partir do seu "corpo máquina de guerra" que a artista transmite sua poética artivista.

O trabalho de Mattiuzzi carrega uma potência singular no cenário da arte contemporânea, uma vez que a construção de suas obras e de seu processo identitário - sempre em devir - desobedece e questiona os estereótipos lançados ao seu corpo preta, mulher, não binária. Seu fazer artístico nasce de sua "máquina de guerra", reinventando não só o campo da arte, como também a sua própria existência e a de outrxs que vão de encontro às suas obras. 
Já a artista capixaba Castiel Vitorino Brasileiro, em sua ação Como Se Preparar Para a Guerra (2018), reveste o seu corpo de espadas-de-Ögún ${ }^{5}$, exercita-se por alongamentos, expulsa agouros ao seu redor com as espadas em punho, gingando, esquivando, golpeando com as pernas em movimentos da capoeira. Ao final da vídeo-performance, deita-se no chão, utilizando suas espadas como travesseiro. Através desta experiência, a artista propóe não só uma forma de cura, mas proteção ao seu corpo preto dissidente, fundamentando-se em uma estética macumbeira que lhe possibilita a fruição da vida.

Em entrevista ao Prêmio PIPA 2019 (2019, on-line), descreve suas práticas artísticas como "uma experiência de incorporação", utilizando-se da arte como "mecanismo capaz de forjar possibilidades de sobrevivência”. Embora sua poética coloque o corpo seu território existencial - e a performance como elementos que se destacam, também produz açóes nos territórios geográficos em que habita, como suas experiências instalativas.

Em diálogo com a performer Jota Mombaça (2019), Vitorino versa sua poética em criaçôes que denomina como "liberdades perecíveis", produzindo ficçôes visionárias que versam sobre a possibilidade de construir modos de vida em um mundo distópico. A partir da afirmativa de que a História tem lhe exigido crueldade, a artista desestabiliza as imposiçôes da racialização e da cisgeneridade pela sua própria existência dissidente, potencializada no seu fazer artístico.

Nas encruzilhadas trazidas pelo artista mineiro Paulo Nazareth conhecemos poéticas que explicitam distintos modos de racializaçáo experimentados por seu corpo, variando de contexto em contexto, sem que, contudo, o artista reivindique uma essência ou identidade fixa. Afirmando sua própria miscigenação, não como parte de um discurso apaziguador de uma suposta democracia racial, mas como elemento trágico e fundante de subjetividades latinoamericanas irmanadas, Nazareth, descendente do povo Krenak pelo lado materno e de negros e italianos pelo lado paterno, desenvolve um trabalho de contramemória através de caminhadas, panfletos, instalaçôes e fotografias, nas quais provocativamente coloca sua imagem de "homem exótico à venda”.

Contra o apagamento de sua origem africana constrói boa parte de sua obra, e na passagem por territórios latino-americanos se deixa fotografar ao lado de outros mestiços e indígenas criando novas formas de perceber sua própria (des)identidade racial, evidenciando, mais uma vez, o quanto a ideia de raça é uma construção moderna-colonial, estabelecida para justificar a expropriação de variados povos e territórios, de cá e de lá do Atlântico. Nazareth faz da errância uma estética, quando caminha, literalmente, do Brasil aos Estados Unidos, sem nunca lavar os pés, levando a poeira do sul ao norte.

"Com essa história de ser mestiço e viajar por América mudo de cor todos os dias... em casa as gavetas não estão tão definidas, mas seguindo mais ao norte tudo é bem arrumado, há o bairro dos negros, dos árabes, dos chicanos e outros tantos. Tem dia que sou niger/ preto/negro, (...) tem dia que sou árabe, paquistanês, índio e outros tantos adjetivos que podem mudar de acordo com os olhos do outro e as palavras da minha boca. Seja como for, às vezes nos 
Estados Unidos da América, quando eu entro em lojas de 'brancos' todo ficam com medo, incluindo eu." (NAZARE$\mathrm{TH}, 2012)$

Se Nazareth faz da ambiguidade como é percebida sua identidade racial ferramenta para questionar modos de (r)existência entre corpos náo brancos nas Américas, essa posição amplifica tensões que vão além de suas ações performáticas entre cidades e fronteiras, e incluem as fricções provocadas pela negociação de seu trabalho no mercado internacional de arte. Ao reunir, junto de suas imagens e textos, vestígios objetuais dessa caminhada, como os chinelos rotos e materiais diversos coletados pelo caminho, Nazareth expóe fragmentos de uma experiência que é sempre maior do que aquilo que o universo da galeria é capaz de acomodar, tensionando também na figura de seu corpo dissidente os cânones da própria instituição.

De modo muito afiado, sua obra opera na reterritorialização de espaços institucionais da arte, relativizando, por exemplo, a pertinência de sua presença na Bienal de Veneza na Itália. Convidado a expor em 2013 e 2015 nesta que é uma das maiores vitrines da arte mundial, Nazareth envia seu trabalho mas recusa nas duas vezes a viagem, seguindo um programa próprio de ação performativa que determina que ele só pode pisar no continente Europeu após visitar todos os países do continente Africano. Diante dessa impossibilidade auto imposta, o artista cria sua própria Bienal, em Veneza, bairro periférico de Ribeirão das Neves, área metropolitana de Belo Horizonte. Veneza, Neves, como um quilombo autorregulado cria seus próprios códigos de funcionamento, desafiando a bienal italiana como centro gravitacional e produzindo formas ativas de territorializar subjetividades dissidentes na arte.
No livro sobre o artista lançado em 2012 pela editora Cobogó a curadora Kiki Mazzucchelli afirma que "a questão racial, embora premente, praticamente inexiste nos atuais debates em torno da arte contemporânea brasileira”. É importante perceber que a produçáo de artistas negrxs vem modificando essa realidade, revertendo os processos de apagamento de suas produçóes e construindo um debate sobre tais questóes, ganhando visibilidade não apenas no Brasil, mas no exterior.

\section{Consideraçóes finais ou Aláfias}

Por meio da relação intrínseca entre poética e política, artistas e curadores negrxs vêm contribuindo não apenas para reescrever a história da arte contemporânea no país, mas também e sobretudo para a produção de novos modos de perceber e conceber corpos dissidentes na sociedade brasileira. Através de uma outra fantasmática do corpo, que, assim como os movimentos neoconcretos compreende a arte para além de um campo de produção de obras, tomando-a como campo de produçáo de sensibilidades e subjetividades, a presença de corpos-casas negrxs em museus, galerias, exposiçôes e bienais expõe as fraturas de nossa sociedade desigual, e inscreve novas corpografias afro-diaspóricas dissidentes no imaginário brasileiro.

Como vimos nos exemplos apresentados acima, a escrita do corpo racializado na arte contemporânea brasileira se anuncia como modo de reivindicar a construçáo de um discurso autorizado sobre si mesmo, resultando em estratégias de sobrevivência e autoinvençáo. São corpos dissidentes criando uma narrativa própria, não como objetos de arte, mas como sujeitos de uma produçáo estético-política, que amplia o que deve e o que pode uma arte brasileira contemporânea tematizar. 
Com sofisticada ironia xs artistas apresentadxs escancaram violências constantemente engatilhadas em direção a seus corpos, rasgando espaços, no mercado da arte, para problemáticas e discussóes que permaneceram por muito tempo à margem - dentro e fora dos espaços institucionais. Seus trabalhos se desenvolvem a partir dos embates de seus corpos dissidentes nas ruas, e as poéticas daí resultantes tratam de formas de sobreviver e rexistir, produzindo destarte seus efeitos de volta na cidade.

Se para toda pessoa negra, as marcas da colonialidade estáo incrustadas na memória da pele, na encruzilhada entre arte e vida os corpos afro-diaspóricos dissidentes produzem subjetividades descolonizadas que rasuram os espaços de circulação desses corpos - sejam as ruas das cidades ou os cubos brancos das galerias.

\section{Notas de fim:}

1. Sankofa é um dos símbolos que compóe o sistema de escrita Adinkra, do povo Ashanti. Consiste num pássaro que está com sua cabeça voltada para trás, agarrando um ovo.

2. É importante salientar que essas redes sócio-religiosas às quais nos referimos faz referência às articulaçóes dos povos africanos de origem nagô na Bahia oitocentista (PINHEIRO, 2015). Demais etnias como os malês, jejes, haussás, congoleses e bantos articularam-se também de formas diversas ao longo de suas lutas na diáspora África - Brasil.

3. Menção ao caso do músico Evaldo Rosa, 51 anos, morto por ação do Exército após ser alveja- do com oitenta tiros na cidade do Rio de Janeiro: $<$ https://brasil.elpais.com/brasil/2019/04/08/politica/1554759819_257480.html>. Acesso em: 19 de agosto de 2019.

4. A posição de Beatriz do Nascimento em torno desta pesquisa é de se desvincular de uma historicizaçáo do negro apenas no que toca ao sistema escravista, tendência de pesquisa em vigor no campo da História do Brasil.

5. Planta herbácea de origem africana.

\section{Referências Bibliográficas}

COMO se preparar para a guerra. Direção de Castiel Vitorino Brasileiro. Vitória, Espírito Santo, 2018. (5 min.), Colorido. Disponível em: <https://www.youtube.com/watch?v=5a8oK9fiOMA\&t=47s $>$. Acesso em: 10 maio 2019.

EXPERIMENTANDO o vermelho em dilúvio II. Direção de Musa Michelle Mattiuzzi. Rio de Janeiro, 2016. (10 min.), Colorido.

FABIÃO, Eleonora. Performance e teatro: poéticas e políticas da cena contemporânea. Revista Sala Preta. Vol.8, n.1. São Paulo: 2008.

JACQUES, Paola Berenstein. Experiência errática. Redobra, Salvador, v. 3, n. 9, p.192-204, 2012. Semestral.

KILOMBA, Grada. A Máscara. Cadernos de Literatura em Tradução, São Paulo, n.16, p. 171-180. 2016

MATTIUZZI, Michelle. "Breviário sobre uma Ação Performática: Só entro no Jogo!". eRevista Performatus, Inhumas, ano 1, n. 5, jul. 2013. 
MOMBAÇA, Jota. "Aqui foi o quilombo do pai $\mathrm{Fe}$ lipe”. 2019. Disponível em: <http://www.buala. $\mathrm{org} / \mathrm{pt} / \mathrm{galeria} / \mathrm{aqui}$-foi-o-quilombo-do-pai-felipe $>$. Acesso em: 20 maio 2019.

NAZARETH, Paulo et al. Paulo Nazareth: Arte contemporânealltda. Rio de Janeiro: Cobogó, 2012. 160 p.

SODRÉ, MUNIZ. O terreiro e a cidade: a forma social negro-brasileira. Petrópolis: Vozes, 1988

Uma lógica perversa de lugar. Eco Pós, Rio de Janeiro, v. 21, n. 3, p.9-16, 05 nov. 2018. NASCIMENTO, Beatriz do. É tempo de falarmos de nós. In: RATTS, Alex. Eu sou atlântica: sobre a trajetória de vida de Beatriz Nascimento. São Paulo: Imprensa Oficial, 2006. p. 109-114.

PINHEIRO, Érika do Nascimento. Candomblé nagô de Salvador: identidade e território no Oitocentos. In: ANPUH - XXV SIMPÓSIO NACIONAL DE HISTÓRIA, 25., 2009, Fortaleza. Anais... . Fortaleza: Anpuh, 2009. p. 1 - 10

PIPA 2019 Castiel Vitorino. Rio de Janeiro: do Rio Filmes, 2019. (3 min.), son., color. Disponível em: <https:/www.youtube.com/watch?v=t5TprwJeS7w>. Acesso em: 20 maio 2019

RUFINO, Luiz. Exu e a Pedagogia das Encruzilhadas. Seminário dos Alunos PPGAS-MN/UFRJ. Rio de Janeiro, 2016. 